\title{
USE OF DECOMPRESSIVE CRANIECTOMY IN THE TREATMENT OF HEMISPHERIC INFARCTION
}

\author{
José Antonio Fiorot Jr.', Gisele Sampaio Silva', Sergio Cavalheiro², Ayrton Roberto Massaro ${ }^{3}$
}

\begin{abstract}
Decompressive craniectomy (DC) has demonstrated efficacy in reducing mortality in hemispheric infarction of the middle cerebral artery. The aim of our study was to compare the outcome of patients submitted to DC to patients treated in a conservative way. Eighteen patients were submitted to DC and 14 received conservative treatment. Neurological status was assessed by the Glasgow Coma Score and National Institutes of Health Stroke Scale score. Mortality, modified Rankin Scale and Barthel Index scores were assessed at 90 days to evaluate outcome. We did not observe reduction in overall mortality and functional outcome in patients submitted to DC. The differences between our group and previously published series are probably related to the neurological status of the patients at the time of therapeutic decision.
\end{abstract}

KEY WORDS: craniectomy, decompressive surgery, middle cerebral artery infarction.

\begin{abstract}
Uso da craniectomia descompressiva no tratamento do acidente vascular cerebral isquêmico hemisférico
Resumo - Craniectomia descompressiva (CD) tem demonstrado eficácia em reduzir a mortalidade em pacientes com infarto hemisférico $(\mathrm{IH})$ da artéria cerebral média. Este estudo avaliou o prognóstico dos pacientes submetidos a CD comparando a pacientes com IH tratados de maneira conservadora. Dezoito pacientes foram submetidos a CD e 14 receberam tratamento conservador. Escala de Coma de Glasgow e Escala de AVC do National Institutes of Health foram utilizadas para graduar o déficit neurológico. A mortalidade, bem como os escores obtidos na escala modificada de Rankin e índice de Barthel foram avaliados em 90 dias. Não foi observada redução de mortalidade nos pacientes submetidos a CD. Essa diferença entre os nossos resultados e os estudos publicados previamente se deve, provavelmente, à decisão cirúrgica tardia em pacientes com sinais clínicos de herniação cerebral.
\end{abstract}

PALAVRAS-CHAVE: craniectomia, descompressão cirúrgica, infarto da artéria cerebral média.

Decompressive craniectomy (DC) has been used to treat intracranial hypertension and cerebral edema associated with several causes. In 1905, Cushing was the first to describe this procedure in the treatment of brain tumors'. Today, DC is the main treatment option for other diseases, such as brain trauma ${ }^{2}$, subdural and epidural hematoma ${ }^{3}$, edema due to subarachnoid hemorrhage ${ }^{4}$, cerebral venous thrombosis with intractable intracranial hypertension ${ }^{5}$, cerebellar infarction ${ }^{6}$ and hemispheric infarction of the middle cerebral artery $(\mathrm{HI})^{7}$. HIs occur in strokes with occlusion of the distal internal carotid artery or the proximal middle cerebral artery. They represent 10 to $15 \%$ of overall strokes ${ }^{8}$. Clinical worsening related to cerebral edema occurs two or three days after the stroke onset, and is associated with high early mortality ${ }^{9}$. DC increases cerebral perfusion, preventing infarction enlarge- ment, and attenuates the expansive effect of edema that leads to cerebral herniation ${ }^{10}$.

Recent international trials showed the importance of $\mathrm{DC}$ in reducing mortality and morbidity in $\mathrm{HI}^{11}$. Few Brazilian studies have analyzed the efficacy of DC in Hls. Nobre et al. worked on a retrospective study, with 34 patients submitted to DC. The authors concluded that men over 50 years have the worst outcome after $D C^{12}$.

The aim of our study was to compare the outcome of $\mathrm{HI}$ patients submitted to $\mathrm{DC}$ to patients treated in a conservative way.

\section{METHOD}

We retrospectively analyzed data of a consecutive series of patients with $\mathrm{HI}$ at the Neurological Emergency Department in the Hospital S.Paulo (UNIFESP-EPM) between February 2002 and

Department of Neurology and Neurosurgery, Universidade Federal de São Paulo, Brazil (UNIFESP/EPM): ${ }^{1}$ Neurologist; ${ }^{2}$ Professor of Neurosurgery; Centro de Medicina Diagnóstica Fleury: ${ }^{3}$ Neurologist.

Received 19 November 2007, received in final form 22 February 2008. Accepted 10 March 2008.

Dr. José Antonio Fiorot Júnior - Rua Aníbal Vieira Rabaiolly 11 - 29065-240 Vitória ES - Brasil. E-mail: fiorotjr@terra.com.br 
August 2006. $\mathrm{HI}$ was an acute ischemic stroke defined by CT as a large parenchymal ischemic lesion that involved at least $50 \%$ of the vascular territory of the middle cerebral artery, or the anterior and middle cerebral arteries territories simultaneously, associated with early brain swelling signs, such as midline shift, compression of the lateral ventricles and basal cisterns. Patients with prior poor clinical conditions ( $m R S \geq 02$ ), those with other critical diseases that affect clinical prognosis, and those who died during surgery were excluded.

Epidemiological data were obtained from medical records. We have selected the clinical neurological parameters Glasgow Coma Score (GCS) and National Institute of Health Stroke Scale (NIHSS) scores and outcome measures modified Rankin Scale (mRS) and Barthel Indice (BI) scores that were systematically registered by the neurological and stroke team upon hospital admission, at the time of therapeutic decision and in a follow-up at 90 days.

This study was approved by the Ethics Committee of Hospital S.Paulo (UNIFESP-EPM) and a signed informed consent was obtained from all patients or their legal representatives.

\section{Statistical analysis}

Statistical analyses were performed using SPSS software version 10.0 (SPSS Inc). A descriptive analysis, including mean \pm SD and median, was used to describe patient data. Parametric data was expressed as mean \pm SD and was analyzed by $t$-test. Nonparametric data was expressed as median and was analyzed by Kruskal Wallis test. Dichotomic data was expressed by percentage and analyzed by $\chi^{2}$ test and Fisher's exact test. Statistical significance was assigned to $p$ value $<0.05$.

\section{RESULTS}

Thirty-two HI patients were analyzed. Eighteen patients were submitted to DC and 14 received conservative treatment $(\mathrm{Ct})$. The therapeutic decision to perform DC was evaluated by the neurosurgeon on call at the neurological emergency department.

\section{Demographic data}

The median age of our patients was $59.1 \pm 18$ years (range 17-93 years). Patients in the operated group were

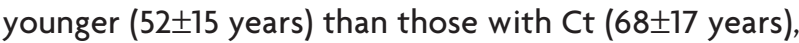
while patients who received $\mathrm{Ct}$ had a higher educational level than those submitted to surgery.

\section{Admission to the hospital}

The mean time between the onset of symptoms and admission to the emergency room was $6.3 \pm 11.3$ hours (range 0.5-50), and did not differ between the two groups. Table 1 summarizes the clinical characteristics of the patients upon admission. The GCS and NIHSS scores did not differ between the two groups. In addition, there was no statistical difference in arterial blood pressure and capillary glucose level, between the two groups at admission. Nearly $15 \%$ of all $\mathrm{HI}$ patients were submitted to thrombolytic treatment.

\section{Therapeutic decision}

The mean time between the onset of symptoms and therapeutic decision among our $\mathrm{HI}$ patients was 35.4 \pm 27.1 hours and did not differ between the two groups. Fifty percent of our patients submitted to DC were treated in less than 24 hours of symptoms onset. However, at therapeutic decision, patients submitted to DC had lower GCS scores than those with $\mathrm{Ct}$. In addition, NIHSS scores were also worse in those selected to DC. There was a rapid neurological deterioration between admission and therapeutic decision in both groups, marked in those patients selected to DC, as demonstrated in Figures 1 and 2. All patients in the DC group had a decreased level of consciousness and almost half of them showed unilateral fixed and dilated pupil at the time of therapeutic decision (Table 2).

Follow-up at 90 days after therapeutic decision

Mortality, GCS, NIHSS, mRS and BI scores did not differ between the two groups at 90 days (Table 3).

\section{DISCUSSION}

Many international studies confirmed that age is the most important predictor affecting outcome in $\mathrm{DC}^{13-15}$.

Table 1. Clinical and neurological parameters at admission in patients with HI.

\begin{tabular}{lccc}
\hline Hemispheric infarction & $\mathrm{DCN}=18$ & $\mathrm{Ct} \mathrm{N}=14$ & $\mathrm{P}$ \\
\hline Admission & & & \\
$\quad$ Mean (median) of time delay from onset to admission (hrs) & $5.4 \pm 8.4(2,0)$ & $7.3 \pm 13.7(2.0)$ & $\mathrm{NS}$ \\
Mean (median) GCS score & $10 \pm 4(12)$ & $12 \pm 2(12)$ & $\mathrm{NS}$ \\
Mean (median) NIHSS score & $17 \pm 7(15)$ & $14 \pm 6(14)$ & $\mathrm{NS}$ \\
Mean systolic arterial pressure (mmHg) & $145 \pm 32$ & $141 \pm 39$ & $\mathrm{NS}$ \\
Mean diastolic arterial pressure (mmHg) & $89 \pm 20$ & $85 \pm 21$ & NS \\
Mean arterial pressure (mmHg) & $109 \pm 22$ & $104 \pm 26$ & NS \\
Mean capillary glucose (mg/dl) & $172 \pm 68$ & $183 \pm 92$ & NS \\
Intra-venous thrombolysis & $22 \%$ & $7 \%$ & NS \\
\hline
\end{tabular}




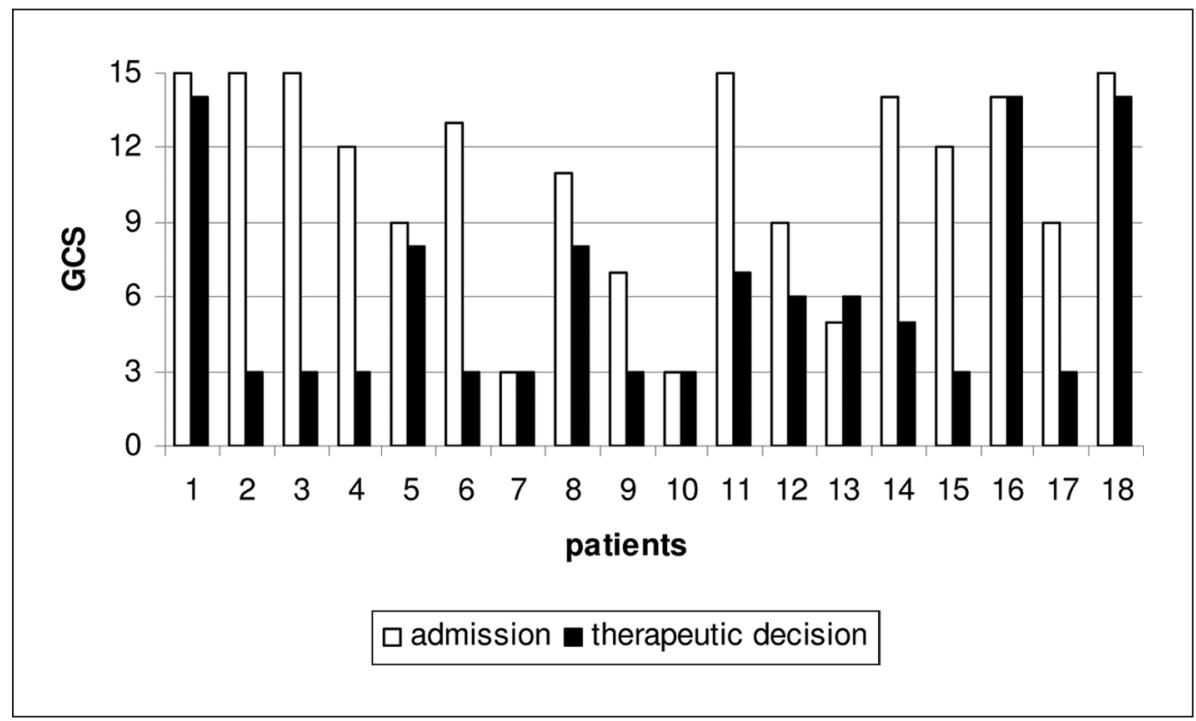

Fig 1. GCS score in DC patients.

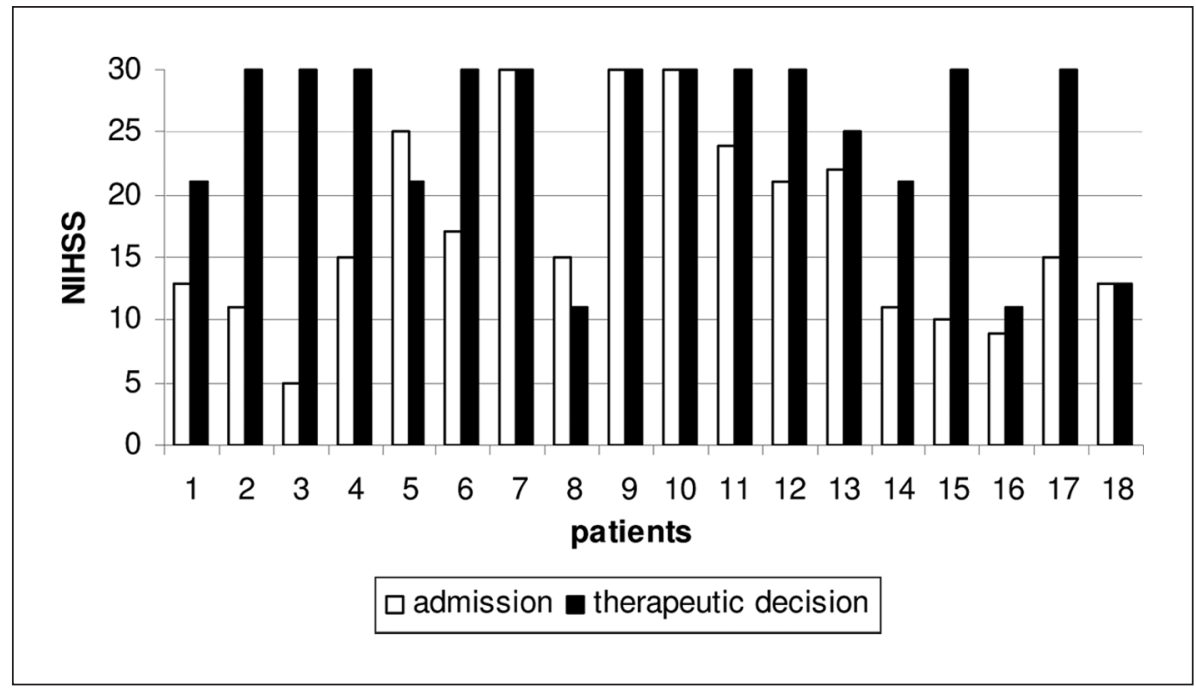

Fig 2. NIHSS score in DC patients.

Table 2. Clinical and neurological parameters at therapeutical decision in patients with HI.

\begin{tabular}{lccc}
\hline Hemispheric infarction & $\mathrm{DCN}=18$ & $\mathrm{Ct} \mathrm{N}=14$ & $\mathrm{P}$ \\
\hline Therapeutic decision & & & \\
Mean (median) time delay from onset (hrs) & $33 \pm 25(25)$ & $37 \pm 29(29)$ & $\mathrm{NS}$ \\
Mean (median) time delay from admission (hrs) & $31 \pm 20(30)$ & $34,7 \pm 27.8(27)$ & $\mathrm{NS}$ \\
Mean (median) GCS score & $6 \pm 4(4)$ & $9 \pm 3(10)$ & 0.016 \\
Mean (median) NIHSS score & $25 \pm 7(30)$ & $19 \pm 7(17)$ & 0.025 \\
Decreased level of consciousness & $100 \%$ & $50 \%$ & 0.001 \\
Anisocoria & $38 \%$ & 0 & 0.01 \\
Treatment with manitol & $56 \%$ & $36 \%$ & $\mathrm{NS}$ \\
\hline
\end{tabular}


Table 3. Outcome parameters at 90 days in patients with $\mathrm{HI}$.

\begin{tabular}{lccc}
\hline Hemispheric infarction & $\mathrm{DCN}=18$ & $\mathrm{Ct} \mathrm{N}=14$ & $\mathrm{P}$ \\
\hline $\begin{array}{l}\text { Follow-up at 90 days } \\
\text { Death }\end{array}$ & $55 \%$ & & \\
Mean (median) GCS score & $11 \pm 3(13)$ & $13 \pm 2(13)$ & $\mathrm{NS}$ \\
Mean (median) NIHSS score & $15 \pm 8(13)$ & $10 \pm 5(10)$ & NS \\
$\mathrm{mRS} \leq 04$ & $50 \%$ & $50 \%$ & NS \\
$\mathrm{BI} \geq 56$ & $12.5 \%$ & $33.3 \%$ & NS \\
\hline
\end{tabular}

Yu Yao et al. conducted a study comparing the effects of DC in older and younger patients. The mortality was $7.7 \%$ in patients with less than 60 years, compared to $33.3 \%$ in those $\geq 60$ years $^{14}$. In a systematic review of DC with 138 patients, Grupta et al. also cited the importance of age ${ }^{15}$. Eighty percent of 75 patients over 50 years had poor functional outcome or death when treated with DC, while in younger patients, these endpoints occurred in only $32 \%$. Our DC patients have been selected within the theoretically ideal age group ( $<60$ years) to obtain good results with this procedure.

Patients in both groups arrived early in the Emergency Department. This is probably due to the severity of the neurological deficits that leads the patient and the family to seek out hospital care immediately ${ }^{16}$. Despite early arrival, the decision to perform DC in our patients was delayed. This time frame between hospital arrival and therapeutic decision-making probably played an important role in the neurological deterioration and the outcome in $\mathrm{HI}$ patients.

Kilincer et al. showed that a pre-surgery GCS $>8$ is an important determinant of a favorable outcome ${ }^{17}$. Performing surgery on several patients with clinical signs of brain herniation was probably one of the most important reasons for the lack of clinical benefits from DC in our group.

Most of the studies on DC in $\mathrm{HI}$ patients evaluated outcome after 90 days. In a study with 118 patients, 63 submitted to DC, Schwab et al. demonstrated the great benefit on mortality reduction in patients with $\mathrm{HI}$ submitted to DC. Results were even better when surgery was performed earlier than 24 hours, causing an extraordinary decrease in deaths and a mild improvement in functional outcome $e^{10}$.

Besides the timing to perform DC in HI patients, neuroimaging seems to be another important tool to select the ideal patient. Der-Yang Cho et al. used diffusion (DWI) and perfusion (PWI) sequences of magnetic resonance (MRI), and proposed the new concept of ultra-early DC $(<6 \text { hours from onset })^{18}$. The authors obtained excellent results, with mortality lower than $10 \%$ and a better functional outcome than prior studies. Thomalla et al. studied the role of early MRI to predict the occurrence of HI. Thirty-seven patients with acute $\mathrm{HI}$ were submitted to DWI, PWI, and MR angiography within 6 hours of symptom onset. Predictors of $\mathrm{HI}$ were as follows for sensitivity and specificity, respectively: apparent diffusion coefficient $(\mathrm{ADC})_{<80 \%}>82 \mathrm{ml}(87 \%$ and $91 \%$ ), time to peak (TTP) $>>4 \mathrm{~s}$ $>162 \mathrm{ml}(83 \%$ and $75 \%)$ and TTP/ADC mismatch ratio $<2.4$ $(80 \%$ and $79 \%)(p<0.05)^{19}$. Although there was a significant difference in the clinical parameters in our patients at the time of therapeutic decision, we could not detect any differences in the outcome at 90 days follow-up visit.

Our initial results were not as encouraging as the previously published ones ${ }^{10}$. We could not observe a significant reduction in overall mortality, when comparing patients treated with $D C$ to $C t$. The lack of benefit of DC in our study group is probably a consequence of performing late surgery in patients with rapidly evolving clinical signs of brain herniation and less salvable brain tissue. This fact may suggest that if patients submitted to $D C$ had been operated in equal neurological conditions that those indicated to $\mathrm{Ct}$, they might have had better outcome.

Early DC, performed within 24 hours from stroke onset, is a well established option of treatment in $\mathrm{HI}$, in which thrombolysis was unsuccessful. Hypothermia maybe another possible early synergic therapy in future trials with $\mathrm{HI}$ patients. When combined to DC, hypothermia seems to reduce the final brain infarction volume, improving neurological outcome ${ }^{20}$. It is obvious that intensive care conditions play an additional important role in the final results of DC. Control of temperature ${ }^{21}$, arterial blood pressure ${ }^{22}$, glycemia ${ }^{23}$ and intracranial pressure ${ }^{24}$ must be rigorous.

Further protocols should improve decision-making for DC to optimize patient selection and minimize treatment delays selecting the patient with acute $\mathrm{HI}$ that will mostly benefit from this therapeutic procedure. Based on our data and reviewing the literature, we may suggest the following criteria: age less than 60 years; early decision for surgery within the first 24 hours of stroke onset; patients with rapidly neurological worsening evaluated by 


\section{GCS and NIHSS scores without signs of brain herniation; and finally subtle large and early acute ischemic lesions detected by the initial CT or MRI.}

ACKNOWLEDGMENTS - The authors are indebted to Dr. Sheila Martins for her technical assistance with statistical analysis.

\section{REFERENCES}

1. Cushing $\mathrm{H}$. The establishment of cerebral hernia as a decompressive measure of inaccessible brain tumors; with the description of intermuscular methods of making the bone defect in temporal and occipital regions. Surg Gynecol Obstet 1905;1:297-314.

2. Guerra WK, Gaab MR, Dietz H, Mueller JU, Piek J, Fritsch MJ. Surgical decompression for traumatic brain swelling: indications and results. J Neurosurg 1999;90:187-196.

3. Cooper PR, Rovit RL, Ransohoff J. Hemicraniectomy in the treatment of acute subdural hematoma: a re-appraisal. Surg Neurol 1976;5:25-28.

4. Fisher CM, Ojemann RG. Bilateral decompressive craniectomy for worsening coma in acute subarachnoid hemorrhage: observations in support of the procedure. Surg Neurol 1994;41:65-74.

5. Stefini R, Latronico N, Cornali C, Rasulo F, Bollati A. Emergent decompressive craniectomy in patient with fixed dilated pupils due to cerebral venous and dural sinus thrombosis: report of three cases. Neurosurgery 1999;45:626-630.

6. Chen HJ, Lee TC, Wei CP. Treatment of cerebellar infarction by decompressive subocciptal craniectomy. Stroke 1992;23:957-961.

7. Rengachary SS, Batnitzky S, Moranz RA, Arjunan K, Jeffries B. Hemicraniectomy for acute massive cerebral infarction. Neurosurgery 1981;8:321-328.

8. Hacke W, Schwab S, Horn M, Spranger M, de Georgia M, von Kummer R. Malignant middle cerebral artery territory infarction. Arch Neurol 1996;53:309-315.

9. Heinsius T, Bogousslavsky J, van Melle G. Large infarcts in the middle cerebral artery territory: etiology and outcome patterns. Neurology 1996;50:341-350.

10. Schwab S, Steiner T, Aschoff A, et al. Early hemicraniectomy in patient with complete middle cerebral artery infarction. Stroke 1998;29:1888-1893.

11. Vahedi K, Hofmeijer J, Juettler E, et al. DECIMAL, DESTINY, and HAM LET investigators. Early decompressive surgery in malignant infarction of the middle cerebral artery: a pooled analysis of three randomized controlled trials. Lancet Neurology 2007;6:215-222.
12. Nobre MC, Monteiro M, Albuquerque AC, et al. Decompressive craniectomy for treatment of intracranial hypertension secondary to large ischemic cerebral infarction: analysis of 34 cases. Arq Neuropsiquiatr 2007;65:107-113.

13. Rieke K, Schwab S, Krieger D, et al. Decompressive surgery in spaceoccupying hemispheric infarction: results of an open prospective trial. Crit Care Med 1995;23:1576-1578

14. Yao Y, Liu W, Yang X, Hu W, Li G. Is decompressive craniectomy for malignant middle cerebral artery territory infarction of any benefit for elderly patients? Surg Neurol 2005;64:165-169.

15. Gupta R, Connolly ES, Mayer S, Elkind MS. Hemicraniectomy for massive middle cerebral artery territory infarction: a systematic review. Stroke 2004;35:539-543.

16. Cho DY, Chen TC, Lee HC. Ultra-early decompressive craniectomy for malignant middle cerebral artery infarction. Surg Neurol 2003;60:227-232.

17. Qureshi AI, Kirmani JF, Sayed MA, et al. Buffalo Metropolitan Area and Erie County Stroke Study Group: time to hospital arrival, use of thrombolytics, and in-hospital outcomes in ischemic stroke. Neurology 2005;64:2115-2120.

18. Kilincer C, Asil T, Utku U, et al. Factors affecting the outcome of decompressive craniectomy for large hemispheric infarctions: a prospective cohort study. Acta Neurochir (Wien) 2005:147:587-594.

19. Cho DY, Chen TC, Lee HC. Ultra-early decompressive craniectomy for malignant middle cerebral artery infarction. Surg Neurol. 2003;60:227-232.

20. Thomalla GJ, Kucinski T, Schoder V, et al. Prediction of malignant middle cerebral artery infarction by early perfusion and diffusion weighted magnetic resonance imaging. Stroke 2003;34:1892-1900.

21. Doerfler A, Schwab S, Hoffmann TT, Engelhorn T, Forsting M. Combination of decompressive craniectomy and mild hypothermia ameliorates infarction volume after permanent focal ischemia in rats. Stroke. 2001;32:2675-2681.

22. Wong AA, Davis JP, Schluter PJ, Henderson RD, O'Sullivan JD, Read SJ. The time course and determinants of temperature within the first $48 \mathrm{~h}$ after ischaemic stroke. Cerebrovasc Dis 2007;24:104-110.

23. Urrutia VC, Wityk RJ. Blood pressure management in acute stroke. Crit Care Clin 2006;22:695-711.

24. Gray CS, Hildreth AJ, Sandercock PA, et al. GIST trialists collaboration. Glucose-potassium-insulin infusions in the management of post-stroke hyperglycemia: the UK glucose insulin in stroke trial (GIST-UK). Lancet Neurol 2007;6:397-406.

25. Frank JI. Large hemispheric infarction, deterioration, and intracranial pressure. Neurology 1995;45:1286-1290. 